\title{
Design of Slow Traffic System in Historic District from the Perspective of Healthy City
}

\author{
Jing HUANG ${ }^{\mathrm{a}}$, Hong XU ${ }^{\mathrm{a}, 1}$ and Rui DING ${ }^{\mathrm{a}}$ \\ ${ }^{a}$ School of Urban Construction, Wuhan University of Science and Technology, Wuhan, \\ China
}

\begin{abstract}
Health is not only derived from a good personal lifestyle, but also from a good external social environment. This article summarizes relevant researches on healthy cities and slow-moving systems at home and abroad, and discusses how to understand the environmental space of historical locations from a human perspective, and use the concept of healthy cities to study the use of various spaces. Taking the Tanhualin Historic District in Wuhan as an example, this paper analyzes the current situation of the Tanhualin Historic District and the existing problems in the transportation system, and proposes a new design model for the slow system design of Tanhualin from the perspective of a healthy city.
\end{abstract}

Keywords. Healthy City, historic district, slow traffic system, Tanhualin

\section{Introduction}

Health is the most precious wealth of mankind and the prerequisite for achieving all goals. With the deepening of people's understanding of the concept of health promotion, since the late 1980s, a new term "healthy city" has appeared more and more frequently in conferences and documents at home and abroad. Under the background of highspeed urbanization, urban traffic tends to be dominated by motorized traffic, while ignoring the important regulatory role of the slow traffic system.

\section{Healthy City}

\subsection{Definition of Healthy City Theory}

A healthy city means that all aspects from urban planning, construction to management are centered on human health, ensuring the healthy life and work of the general public, and becoming a healthy population, a healthy environment and a healthy society required by the development of human society. The overall development of organic integration [1].

1 Hong Xu, School of Urban Construction, Wuhan University of Science and Technology, Wuhan,China; E-mail: xuhong@wust.edu.cn. 


\subsection{Healthy City Practices Abroad}

The Healthy City Initiative is being carried out on a global scale. As of 1992, 92 cities in 30 countries have actively responded to the European Healthy Cities Action Plan proposed by the World Health Organization. These countries and cities have carried out urban greening, integrated ecology and health in urban planning, and established helpful In the management mechanism of urban sanitation project management and inter-departmental decision-making mechanism [2].

\subsection{Domestic Healthy City Practice}

In October 2006, the 2nd World Healthy Cities Alliance Conference was held in Suzhou. In 2008, the Ministry of Health proposed that China will implement the "Healthy China 2020" strategy: by 2020, my country will establish a relatively complete basic medical and health system covering urban and rural residents, and the health level of the entire population is close to that of a moderately developed country [3].

\section{Historic District}

\subsection{Historic Districts and Slow Traffic System}

The intensity of land development in historical blocks is relatively high, but the overall road width of the roads in historical blocks is narrow, the road structure is poor, and the historical protection buildings in the historical blocks restrict its transformation. The increase in traffic and population has also increased traffic pressure in historic districts. The shaping of the slow traffic system in historical blocks can help reduce traffic congestion, improve the comfort of users, and increase the sense of belonging. Improve environmental safety [4].

\subsection{Historic District and Healthy City}

In the study of the South Xinhua Street section of Xicheng District, Beijing from the perspective of health, Ying Huang and Yifang $\mathrm{Xu}$ [5] put forward suggestions in order to form a healthy living environment in the historic districts, including improving the slow-traveling environment on roads and improving pedestrian friendliness. From the perspective of user experience, reducing the probability of interrupting the walking path can improve the walking comfort of urban residents. From the psychological level, returning to a slow-traffic space suitable for human scale is more conducive to residents' health.

\section{Slow-Traffic System}

\subsection{Historic District and Healthy City}

The basic characteristics of slow traffic can be summarized as follows: 
(1) Connect various public spaces in the city to meet the needs of residents for travel, relaxation, and communication.

(2) Short-distance travel has obvious advantages. Use manpower as the driving force for transportation, and the travel speed is low; the travel distance is relatively short, generally less than 3 kilometers.

(3) Green and environmental protection, in line with the requirements of sustainable development, but also beneficial to the physical and mental health of residents [6].

\subsection{Research on Slow-Traffic System Abroad}

Take Copenhagen as an example. Due to its high-quality urban slow-moving system, the car ownership rate of Copenhagen residents is only $22.3 \%$, while $36 \%$ of residents rely on bicycles to commute. The bicycle road network in the urban area of Copenhagen exceeds $360 \mathrm{~km}$, covering the central area. Bicycle lanes in the urban area are mainly divided into independent bicycle lanes and bicycle lanes accompanied by cars. Among them, the bicycle-only road surface of the latter is $7 \sim 12 \mathrm{~cm}$ higher than the motor vehicle lane and is isolated by curbs [7].

\subsection{Domestic Slow-Traffic System Research}

Taking Zhuhai as an example, the slow-moving system planned by Zhuhai City presents a slow-traffic system layout of "seven groups and four belts". There are several slow-moving circles in each group, and each slow-moving circle generally has one or two commercial axis or landscape axis, and a certain range of slow-moving circles is formed by combining the axis with surrounding resources [8].

\section{Tanhualin Historic District}

\subsection{Status Quo of Tanhualin Historic District}

From the street perspective, the scale and tortuous changes of the street affect people's perception of the historical block. The main street of Tanhualin Historic District is Tanhualin Street. After several repairs, Tanhualin Street has been paved with blue stone floor tiles. Parking lots should be added in Tanhualin Historic District to meet people's basic traffic needs and fire protection requirements.

The main street of Tanhualin Historic District is now equipped with road lifting columns (figure 1), but only external vehicles are intercepted, and local residents' motor vehicles can still enter the historic district. 


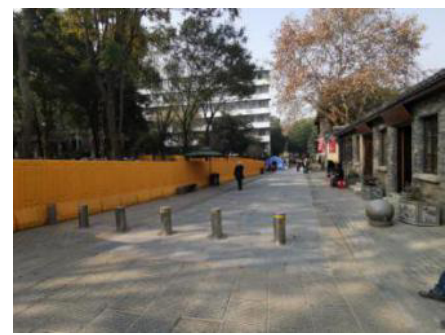

Figure 1. Lifting column on Tanhualin Street Road. (Source: Self-photographed by the author)

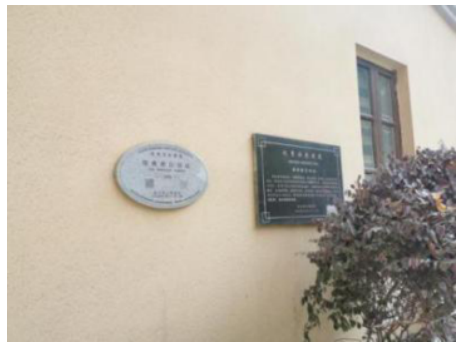

Figure 2. The former site of the Swedish parish. (Source: Photo by the author)

From the point of view of nodes, nodes are places where roads intersect and people are scattered. The environment is quiet and the building facades and public facilities of the road nodes increase the ornamental value of the nodes.

From the point of view of signs, moderately add characteristic signs and landscape sketches in places where roads converge, increase the degree of recognition of space, and guide people's viewing routes. There are many historical buildings in Tanhualin District, such as Renji Hospital, the former site of the Swedish Diocese (figure 2). The reduction of pedestrian traffic speed can create more diverse spaces and make the space of historical buildings more dynamic [9].

\subsection{Problems in Tanhualin Historic District}

Through investment promotion and the influx of a large number of shops, the Tanhualin Historic District is too commercialized. The number of small merchants and hawkers has gradually increased. The streets where road lifting columns are installed are only west of Yanzhi Road. For one part, many local residents' motor vehicles can still drive into Tanhualin Street, making the narrow streets more crowded, and may even cause safety hazards during peak passenger flow. When solving the hidden hazards of motor vehicles and pedestrians, it is also necessary to consider the local area. Residents' parking problem. Bicycle lanes and walking lanes are not distinguished, and some bicycles and electric vehicles run faster, and they are likely to cause friction and collision with pedestrians, causing certain safety hazards.

\subsection{Tan Hualin Slow Traffic System from the Perspective of Healthy City}

First, the block adopts the slow traffic mode of "walking + bicycle". Wuhan is a plain city, and the road height does not fluctuate much. Tanhualin Historic District is located in a dense commercial area in the center of Wuhan, and it is also a tourist and sightseeing area. The Tanhualin Historic District has the characteristics of narrow roads, large flow of people, easy traffic jams, and mixed traffic between people and vehicles. In view of the above characteristics, the Tanhualin Historic District should adopt the slow traffic mode of "walking + bicycle" to avoid motor vehicles from entering the block, and adopt certain isolation measures between the walking path and the bicycle path to avoid collisions between bicycles and pedestrians. Ensure that the safety of pedestrians is guaranteed (figure 3). 


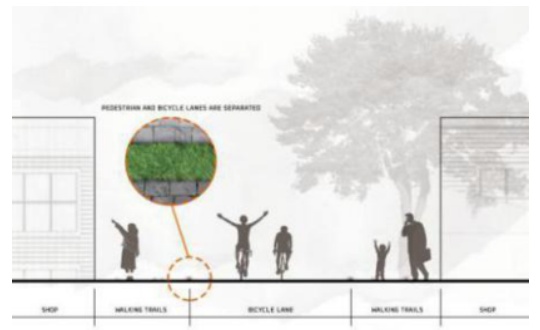

Figure 3. Cross-section of Tanhualin Street Road. (Source: drawn by the author)

The Tanhualin Historic District includes the main street Tanhualin Street and the branch roads on both sides. The width of Tanhualin Street is more than five meters. There are many historical buildings on both sides, which cannot widen the original road width. Combined traffic mode; the branch roads on both sides are relatively narrow, and the road width is less than three meters. For safety reasons, it is suitable to set up only walking paths.

Second, create diversified walking trails. The pedestrian traffic system is designed to fully consider the needs of pedestrians and has a high level of walking comfort; the walkway is set closer to the shops along the street on both sides, so that pedestrians can create a unique pedestrian street through the distribution of commerce along the street, and strengthen the communication between people Communication with businesses along the street; pedestrian facilities that adapt to seasonal changes can be configured, such as pavements with different colors and patterns for different seasons on the pedestrian path, to enhance the interest of the pedestrian path and attract users to choose the way of walking to use the road.

Third, create convenient bicycle lanes. The bicycle lanes in the block are mainly distributed in Tanhualin Street, the main street, and multiple shared bicycle rental points are set up in the block to attract users to choose to use bicycles to explore the historical streets of Tanhualin. At the same time, it provides local residents with alternative transportation methods for driving motor vehicles. Residents can park their motor vehicles in the parking lot and choose to walk or bike home to avoid potential safety hazards caused by motor vehicles (figure 4). Due to the narrow roads in the block, the use of height difference to isolate the walking path and the bicycle path may affect the fire exit. The walking path and the bicycle path are separated by green vegetation, which can ensure the safety of pedestrians and ensure the smoothness of the road.

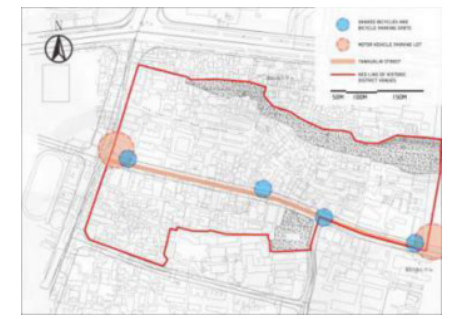

Figure 4. Schematic diagram of bicycle and motor vehicle parking spots in Tanhualin Historic District. (Source: drawn by the author) 
Fourth, set up centralized parking lots. Set up a parking lot on the east and west sides of Tanhualin Historic District to concentrate the motor vehicles parked in the block; set up road lifting columns on the east and west sides of Tanhualin, making Tanhualin Street a completely "walking + bicycle" mode the way.

\section{Conclusion}

At the beginning of 2020, the outbreak of the COVID-19 disease gave us a new understanding of the importance of healthy cities and healthy living environments. Health depends not only on good health services or personal lifestyles, but also on supportive material and social environments.

Domestic research on theories and methods of slow traffic planning is still in its preliminary stage. From the concept of slow traffic to the emergence of some research results, the research on domestic slow traffic planning theories and methods will go through a long stage.

\section{Acknowledgments}

This works was financially supported by the National Natural Science Foundation of China(Grants\#41771473), Key research projects of philosophy and social sciences of Hubei Provincial Department of Education (Grants\#20D025).

\section{References}

[1] Xuan ZL, Fu H. Urbanization and healthy cities. Chinese Public Health. 2003 Feb; (02): 112-114.

[2] Li LP. Healthy city planning abroad. Planners. 2003 Dec; (S1): 40-43.

[3] Chen LQ. Healthy city construction and its development trend. Chinese Market. 2010 Aug; (33): 50-63.

[4] Ku CC. Research on the Slow Moving System in Historic Districts. Wuhan University. 2017 May.

[5] Huang Y, Xu YF. Considerations on the reconstruction of the external human settlement environment of urban historic districts from the perspective of health: A case study of South Xinhua Street, Xicheng District, Beijing. Research on Heritage and Conservation. 2019 Apr; 4(04): 57-60.

[6] Yun MP, Yang XG, Li S. Brief introduction of slow traffic system planning. Urban Transportation 2009 Mar; 7(02): 57-59.

[7] Liu Y, Chen KJ. Enlightenment of slow traffic revival in foreign cities. Transportation World 2017 Jul; (20): 8-10.

[8] Li CY. Research on Urban Slow Traffic Planning Method. Chang'an University. 2011.

[9] Zhang JG, Liu SL. Study on the protection of landscape features in historical and cultural blocksTaking Tanhualin historical and cultural blocks in Wuhan as an example. Popular Literature and Art. 2017 Dec; (24): 95-96. 